\title{
Strengthening Thawed Permafrost Base Railway Embankments Cutting Berms
}

\author{
Sergey Kudriavtcev ${ }^{1}$, Vladimir Paramonov ${ }^{2}$, and Igor Sakharov ${ }^{3, *}$ \\ ${ }^{1}$ Far Eastern State Transport University, 680021 Seryshev str. 47, Khabarovsk, Russia \\ ${ }^{2}$ St. Petersburg State Transport University, 190031 Moskovsky pr. 9, Saint-Petersburg, Russia \\ ${ }^{3}$ Saint-Petersburg State University of Architecture and Civil Engineering, 190005, 2-nd \\ Krasnoarmeiskaya st. 4, Saint-Petersburg, Russia
}

\begin{abstract}
The paper presents the results of a long-term survey of freeze and thaw action conducted at the railroad sections under reconstruction on the permafrost area of the second line of the Baikal-Amur Mainline. The thermophysical research of freeze and thaw action was carried out as well as the calculation of stress-strain distributions and deformation ranges of the roadbed and the subgrade support. The calculations were made by the numerical modeling method with the «FEMmodels» complex. The modeling results help choose the roadbed rational designs that decrease the volumes of deformations to the acceptable ones.
\end{abstract}

\section{Introduction}

When developing new construction projects and reconstructing the existed ones, the whole of known methods to stabilized the subgrade support on permafrost soils is used. There is no reason to believe these methods are innovative in many ways because most of them are known from the times of construction the Baikal-Amur Mainline and its first period of exploitation. However, they have not been much spread and used either at that time or now.

It is considered, for example, that the methods of keeping the subgrade support frozen are not acceptable in the eastern part of the Baikal-Amur Mainline. As there would be no alternative to Design and Construction Principle II, no preventive measures providing stability of the subgrade support were put forward. When implementing Principle II, the only method of compensating the subsidence was to make some width and height reserves that allow the followed corrections of deformations with upgrades on ballast and side filling ups. Besides, the plastic yielding of heave deformations caused by an annual freeze-thaw cycle in wet soils was not taken into account.

A vivid example of the above said is a carried out project of a railway detour around the Bureya Hydropower Station in 2007. The mistakes made when constructing the BaikalAmur Mainline such as wide berms, ill-provided drain, underestimated volume of postconstruction subsidence, have discredited the application of Principle II. It can be reasonably used when the shift component in the subgrade support subsidence is excluded. Unfortunately, currently there is no shared opinion on this issue among the permafrost

\footnotetext{
Corresponding author: tgasu.sakharov.igor@mail.ru
} 
construction professionals. The problem of eliminating the shift deformations in the subgrade support during construction and especially in the long-last period of roadbed exploitation have not been essentially solved in the given region.

It is reasonable to use the mortised berms of stones wrapped in geosynthetic nets that keep the structures solid in thawed toes to decrease or avoid shift deformations.

\section{Numeric modeling processes of freezing, frost heaving and thawing}

A long-term observation and survey of the roadbed of the Baikal-Amur Mainline have been resulted in the soil survey reports, the analysis of gauge stability in warm and cold seasons according to a monitoring of the track measurement car and the aerographics observation data. They confirm that the rock cooling structures of berms and graded rock-fill on the roadbed slopes are reasonable as a project. The technical characteristics of the structures composed of graded rocks were developed and tested by the Tyndinsky Permafrost Station in the given cryological area and have shown their effective work for more than 20 years.

The numerical modeling was carried out in the programming complex «FEM-models» developed by the geotechnical engineers under the guidance of Prof. V. M. Ulitsky. The «Termoground» program is a component part of the complex which allows to research dimensionally by the finite element method the freeze, heave and thaw processes in a year cycle. The numerical problem solution of freeze, heave and thaw processes is modeled in two stages. The first stage, thermotechnical, is resulted in obtaining data on the temperature and wet fields for every period of time. The second stage is resulted in obtaining data on stress and strain conditions of soils that appear in the subgrade support because of the heave and thaw processes.

The model of the thermophysical processes in the «Termoground» program is based on the model of freeze, heave and thaw processes of N. A. Tsytovich, Ya. A. Kronik and V. F. Kiselev. The program calculation supposes that the area with the structure is divided into the finite elements with the same temperature and soil characteristics. Actual on the upper bound the time-variant heat flow rate is relevant to the air temperature and the coefficient of heat transfer.

The initial and limit conditions are assigned into the simulation model, thus the thermotechnical problem is solved to obtain the temperature and wet fields for every period of time. The initial conditions are the soil temperatures in depth; the limit conditions are the soil surface temperatures in time.

The numeric modeling was done on the FEM-models program complex developed by geotechnical engineers in St.Petersburg, Russia (Kudriavtcev S. et al., 2003, Kudriavtcev S. et al., 2012, Kudriavtcev S. et al., 2013). A component of the FEM-models is the "Termoground" program which helps study process of freezing, frost heaving and thawing in a year cycle in spatial programing of numerical modeling by the method of final elements. The core of a mathematical modeling of thermophysical processes in "Termoground" program is the model of high ice, thawed and frozen soils offered by N.A. Tsytovich, Y.A. Kronik and V.F. Kiselev. The task of numeric modeling of freezing, frost heaving and thawing is solved in two stages. Firstly, the thermotechnical part is implemented where moisture and temperature fields are determined for every period of time. Secondly, the stress strain behavior of soils in foundation is determined in the processes of frost heaving and thawing (Kudriavtcev S. et al., 2003).

General equation describing the freezing and thawing processes for a transient thermal regime in a three dimensional soil space can be expressed as following: 


$$
C_{t h(f)} \rho \frac{\partial T}{\partial t}=\lambda_{t h(f)}\left(\frac{\partial^{2} T}{\partial x^{2}}+\frac{\partial^{2} T}{\partial y^{2}}+\frac{\partial^{2} T}{\partial z^{2}}\right)+q_{V}
$$

where $C_{t h(f)}$ - specific heat of soils (frozen or thawed), J/kgK; $\rho$-soil consistency, $\mathrm{kg} / \mathrm{m}^{3} ; \mathrm{T}$ - temperature, $\mathrm{K} ; \mathrm{t}$ - time, $\mathrm{c}{ }^{\lambda}{ }^{t h(f)}$ - thermal conductivity of soil (frozen and thawed), W/mK; $\mathrm{x}, \mathrm{y}, \mathrm{z}$ - coordinates, $\mathrm{m}$; qv- internal heat source capacity, $\mathrm{W} / \mathrm{m}^{3}$.

Under steady conditions the flow, inbound and outbound, in/from the elementary unit of soil is the same atany time. Thus, as the lefthand side of the equation is eliminated, the equationis reduced to:

$$
\begin{gathered}
\lambda\left(\frac{\partial^{2} T}{\partial x^{2}}+\frac{\partial^{2} T}{\partial y^{2}}+\frac{\partial^{2} T}{\partial z^{2}}\right)+q_{V}=0 \\
C_{t h(f)}=C_{t h(f)}+L_{0} \frac{\partial W_{W}}{\partial T}
\end{gathered}
$$

Where $C_{\text {th(f) }}$ - volume specific heat of thawed or frozen soil; $L_{0}=335 \times 106 \mathrm{~J} / \mathrm{m}^{3}=335$ $\mathrm{x} 103 \mathrm{~kJ} / \mathrm{m}^{3}=8975 \mathrm{Btu} / \mathrm{ft} 3=79760 \mathrm{kkal} / \mathrm{m}^{3}$ - water-ice latent heat of transition; Ww moisture content of unfrozen water.

The volume specific heat $\mathrm{C}_{\text {th(f) }}$ can be presented graphically on the heat exchange curve in thawed and frozen areas as shown in Figure 1.

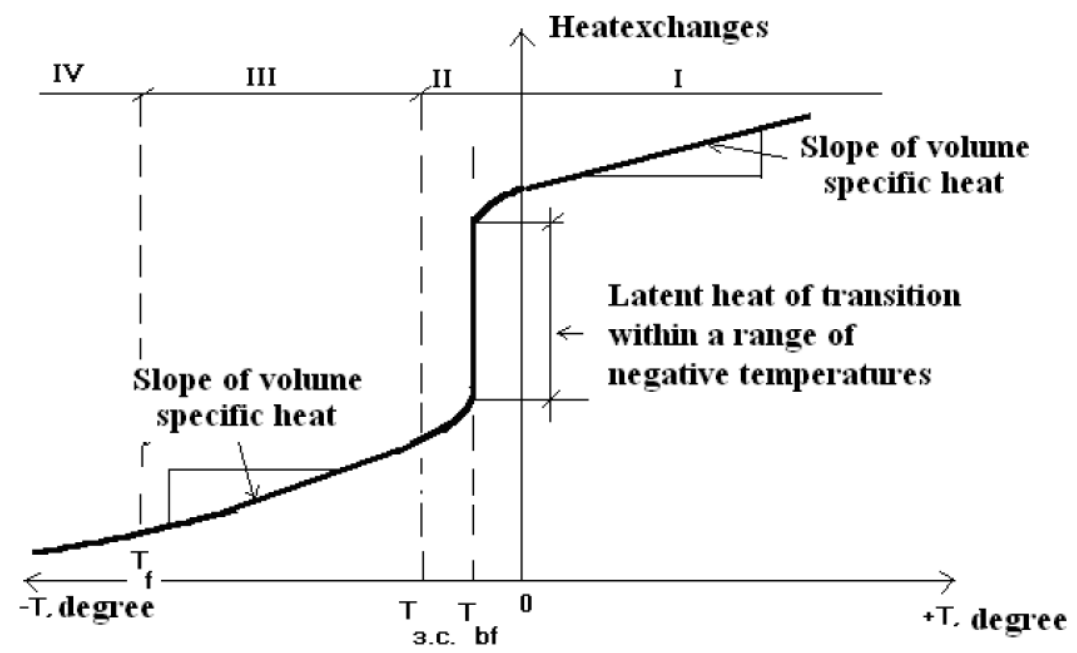

Fig. 1. Curve of heat exchanges in soil (freezing-thawing).

The term $\mathrm{L}_{0} \frac{\partial \mathrm{W}_{\mathrm{W}}}{\partial \mathrm{T}}$ in Fig.1 represents changes in latent heat of transition within a range of negative temperatures absorbed or yielded by soil due to changes in ground water phase.

Average soil moisture within a migration layer (amount of migration moisture is considered) is determined from the formula: 


$$
w_{w f}=\frac{\mathrm{Q}_{\mathrm{wf}}}{\gamma_{\mathrm{d}}}
$$

Where $\mathrm{Q}_{\mathrm{wf}}$ - amount of migration moisture; $\gamma \mathrm{d}$ - specific weight of dry soil. The mass of migration soil is determined from the formula:

$$
Q_{w f}=q_{w f} \cdot A \cdot t
$$

Where $\mathrm{q}_{\mathrm{wf}}$ - migration flow intensity of moisture; A- cross-sectional area of migration flow; $\mathrm{t}$ - impact time.

As the migration flow is measured in the unit volume, the specific weight of dry soil $\gamma$ dequals to the mass of dry soil $Q_{d}$. Thus, the delta of average migration moisture per time period equals:

$$
\Delta W_{w f}=\frac{Q_{w f}}{Q_{d}}
$$

Having analyzed all existed ratios of the moisture increment $\Delta \mathrm{w} 1$ (fr. unit) versus the rate of freezing $\mathrm{V}_{\mathrm{f}}(\mathrm{m} / \mathrm{time})$ in different types of soil, relevant approximating functions were selected . Average values of the approximating functions of ratios of moisture increment $\Delta \mathrm{w} 1$ versus rate of freezing $\mathrm{V}_{\mathrm{f}}$ on the freezing front for different soils are expressed by a common formula as follows:

$$
\Delta W_{w f}=b \cdot \exp ^{c \cdot v}
$$

where $\mathrm{V}$ - rate of soil freezing, $\mathrm{b}, \mathrm{c}$ - empirical coefficients.

On the basis of abundant surveys in frost soil territories of Russia there are two maximums of ground water level fluctuations a year: spring and autumn.

The spring maximum is characterized by the highest level in a year.

The specialists from the Far Eastern State Transport University have a great experience in this field; their concept statements on the mortised berms design are included in "The technical standards for stability of deforming roadbeds on thaw subgrade supports in permafrost" (1993).

The cross-section of $1400 \mathrm{~m}$ long (Fig. 2) is projected on the basis of a geotechnical conditions analysis, and it solves the problem of soil stability in the subgrade support without restoration of its frozen condition.

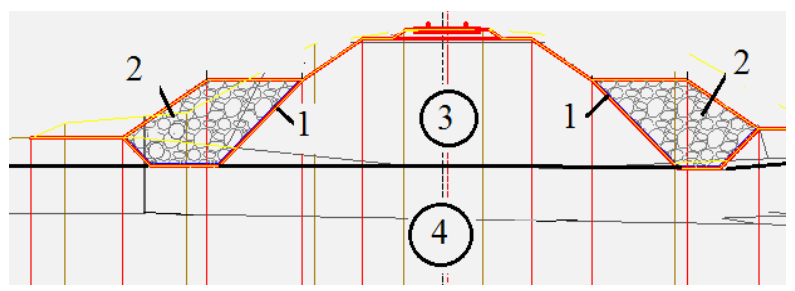

Fig. 2. Cross-section profile of railway embankment: 1- geogrid; 2 - stone; 3 - thaw soils; 4 permafrost soils.

The results of thermophysical processes calculations without and with increased permafrost base berms are shown in Figure 


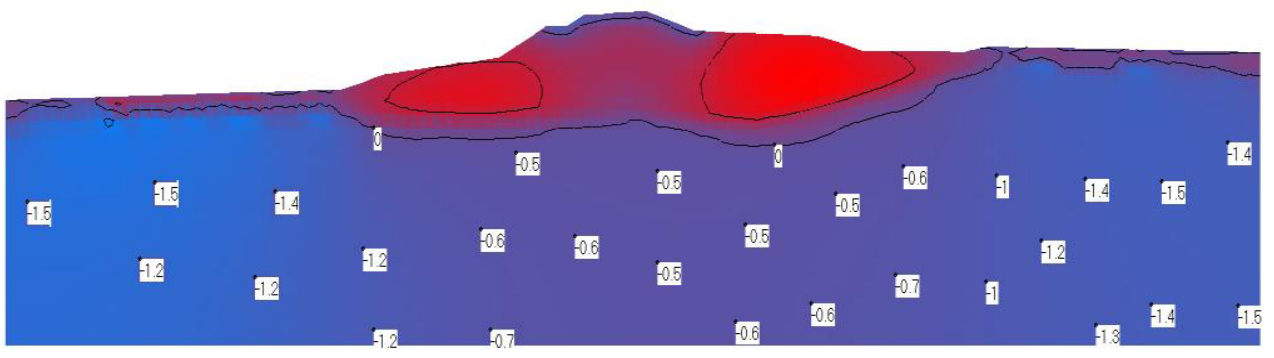

Fig. 3. Temperature distribution for 10 year of operation without increased

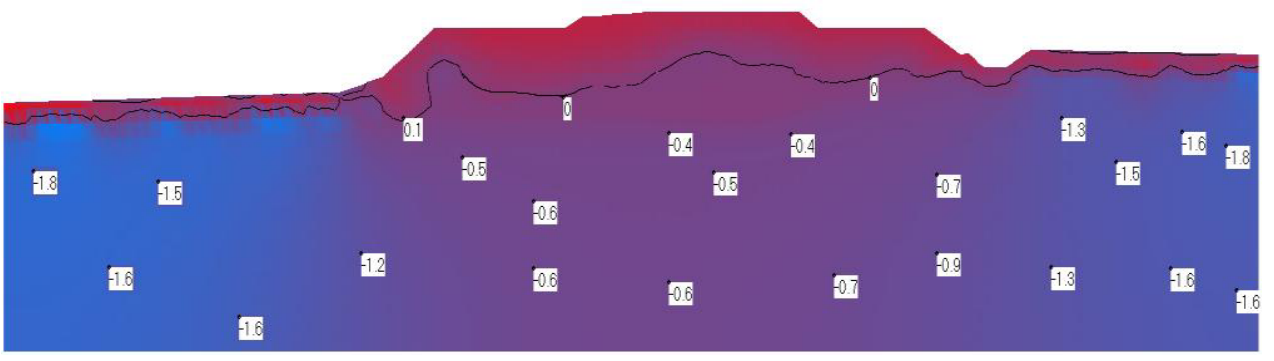

Fig. 4. Temperature distribution for 10 year of operation with increased.

This solution is considered optimal due to several reasons:

- as it is impossible to remove a weak thaw soil from under the subgrade support, some conditions preventing fill wash-out appear. The thaw soil being weak because of annual deep freeze is heaved. The near-toe area is heaved when a multiple rise and settlement of the slope lead to soothing of its gradient;

- a mortising part of the berms prevents heaving and creates the conditions for so called soil consolidation of the subgrade support under the main area. Besides, it provides a service lane during all the works on the site while the traffic keeps on active; moreover, the moss layer is not disturbed in the right-of-way;

- the berm's superstructure of graded stone creates the gravitational stability by its weight, tolerates uneven upper bound of permafrost and prevents further degradation of permafrost. In case the water drain works well, the cooling part of the berm would create a grout curtain of a frozen area around the berm's centerline in $3-5$ years.

Fig. 5 shows the roadbed cross-section with the mortised berm design.

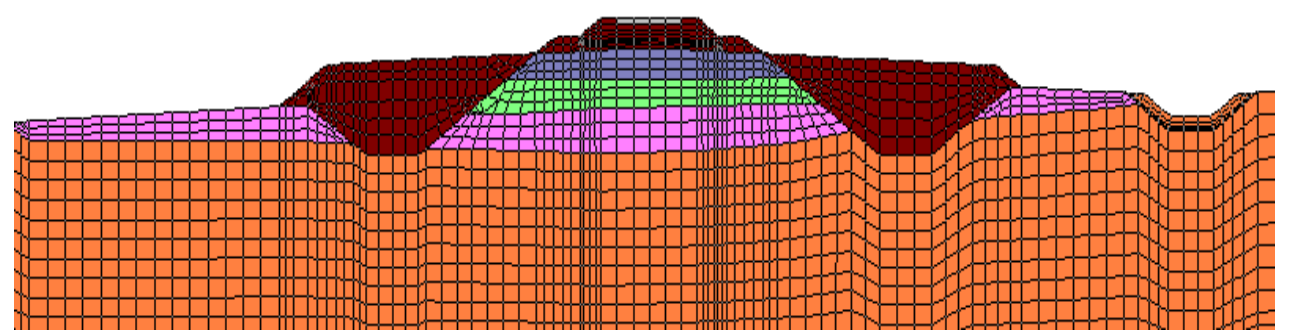

Fig. 5. Roadbed design with subgrade support reinforced by mortised berm.

Fig. 6 shows isolines of vertical displacements in the body and the subgrade support caused by railway traffic. The volume of vertical deformations has decreased by more than three times and is equal to $9 \mathrm{~cm}$. 


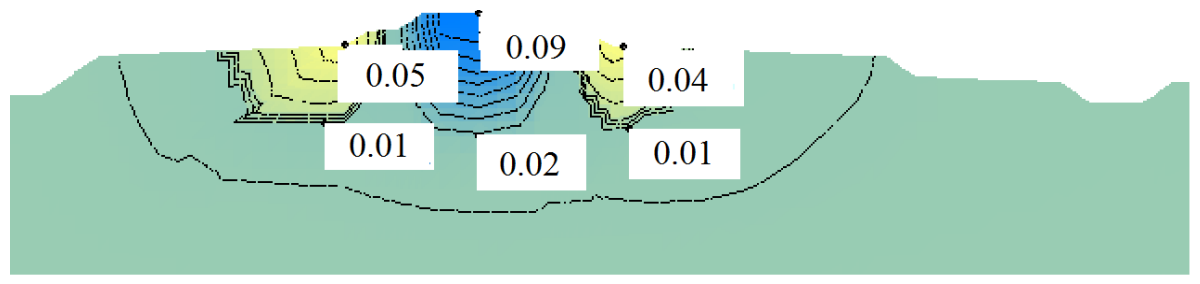

Fig. 6. Isolines of vertical displacements.

Fig. 7. shows the isolines of horizontal displacements in the body and the subgrade support caused by railway traffic. The volume of horizontal deformations has decreased by more than three times and is equal to $6 \mathrm{~cm}$.

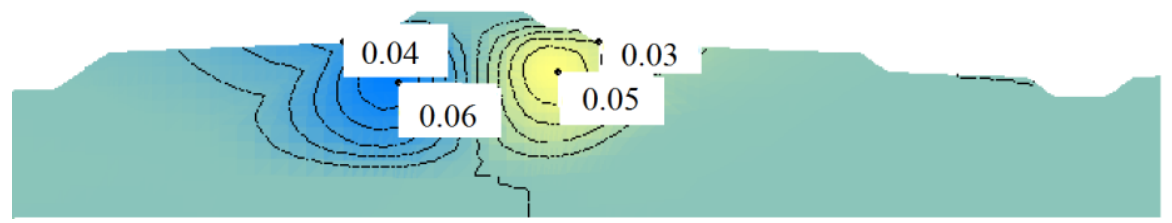

Fig. 7. Isolines of horizontal displacements.

\section{Conclusion}

The results of thermophysical calculations showed that the permafrost temperature under the body of railroad rises from $0.6^{\circ} \mathrm{C}$ up to $1.0^{\circ} \mathrm{C}$ forming a thawing basin.

The depth of soil thawing in field conditions beyond the embankment equals to $1.1-1.8 \mathrm{~m}$.

The results of the calculations are suitable for a water drain system being in a working order while the defrost influence of atmospheric water infiltration as well as creep of water through the body and the embankment base are not taken into account.

The calculations were done for the applied cooling measures in a form of rock fill on the slopes and the mortised berms on the both sides of the embankment. These cooling and stabilizing measures keep the permafrost frozen and raise its upper bound from $3.0 \mathrm{~m}$ to 4.1 $\mathrm{m}$. The combined calculations accounting the traffic loads on the embankment design were carried out to assess the efficiency effect of the mortised berms and the rock fills on the stress and strain condition of the embankment.

The results of the calculations for stress and strain state have proved the efficiency of rock fill on the slopes and the berms mortised into the toe soils.

The vertical and horizontal deformations of the roadbed of the railway embankment do not outreach $5 \mathrm{~cm}$ for the period of thaw maximum.

\section{References}

1. S.A. Kudryavtcev, Soil Mechanics and Foundation Engineering, 41(5), 177-184 (2004)

2. S.A. Kudryavtcev, U.B. Berestyanyy, T.U. Valtseva, N.V. Barsukova, 1st International conference on new developments in geoenvironmental and geotechnical engineering, 423-427 (2006)

3. S.A. Kudryavtcev, V.N. Paramonov, M.B. Lisuk, Asian Conference on Permafrost. Abstracts. Lanzhou (2006)

4. S.A. Kudryavtcev, U.B. Berestyanyy, T.U. Valtseva, L.A. Arshinskaya, A.Z. Zussupbekov, International workshop on scrap tire derived geomaterials. «Scrap Tire 
Derived Geomaterials. Opportunities and challenges». Taylor \& Francis Group/Balkema (2008)

5. S.A. Kudryavtcev, U.B. Berestyanyy, T.U. Valtseva, The Proceeding of the International Geotechnical Symposium "Geotechnical engineering for disaster prevention \& reduction", 348-351 (2007)

6. S.A. Kudryavtcev, V.N. Paramonov, The Proceeding of the International Geotechnical Symposium "Geotechnical engineering for disaster prevention \& reduction", 467-470 (2007)

7. S.A. Kudryavtcev, V.N. Paramonov, A.L. Nevzorov, E.V. Kriger, The Proceeding of the International Geotechnical Symposium "Geotechnical engineering for disaster prevention \& reduction", 600-605 (2007)

8. S.A. Kudryavtcev, Y.B. Berestyanyy, T.U. Valtseva, V.N. Chylichkov, D.G. Tsvigunov, 8th International Symposium on Cold Region Development, 37-38 (2007)

9. S.A. Kudryavtcev, Y.B. Berestyanyy, T.U. Valtseva, Ground Improvement and Geosynthetics for Human Security and Environmental Preservation, 493-500 (2007)

10. S.A. Kudryavtcev, D.G. Tsvigunov, Extended Abstracts. Ninth International Conference on Permafrost. Institute of Northern Engineering. University of Alaska, $155-156(2008)$

11. S.A. Kudryavtcev, Y.B. Berestyanyy, T.U. Valtseva, E.D. Goncharova, Ninth International Conference on Permafrost. Institute of Northern Engineering. University of Alaska, 323-324 (2008)

12. S.A. Kudryavtcev, Y.B. Berestyanyy, T.U. Valtseva, Fourth International Conference on Scour and Erosion, 651-654 (2008)

13. S.A. Kudryavtcev, Y.B. Berestyanii, E.V. Fedorenko, T.U. Valtseva, R.G. Mikhailin, 3rd International Geotechnical Symposium on Geotechnical Engineering for Disaster Prevention and Reductio, 18-25 (2009)

14. S.A. Kudryavtcev, Y.B. Berestyanii, T.U. Valtseva, R.G. Mikhailin, E.D. Goncharova, 14th Conference on cold regions engineering, 45-48 (2009)

15. S.A. Kudryavtcev, V.N. Paramonov, I.I. Sakharov, The freezing and thawing of ground (practical examples and finite-element calculations) (Saint-Petersburg, 2014)

16. S.A. Kudryavtsev, Y.B. Berestyanyy, E.D. Goncharova, The 23rd International Offshore (Ocean) and Polar Engineering Conference Anchorage, 562-566 (2013)

17. S.A. Kudryavtsev, Y.B. Berestianyi, T.Y. Valtseva, A.V. Kazharskyi, E.D. Goncharova, The 1st International Symposium on Transportation Soil Engineering in Cold Regions. Sciences in cold and arid region, 404-407 (2013)

18. S.A. Kudryavtsev, A.V. Kazharskyi, The 5th International Geotechnical SymposiumIncheon, Geotechnical engineering for disaster preventional \& reduction. Incheon, (2013)

19. S.A. Kudryavtsev, Y.B. Berestianyi, T.U. Valtseva, R.G. Mikhailin, E.D. Goncharova, The 24rd International Offshore (Ocean) and Polar Engineering Conference (2014)

20. S.A. Kudryavtsev, Y.B. Berestianyi, A.V. Kazharskyi, E.D. Goncharova, The 10th International Symposium on Permafrost Engineering in Cold Regions. Sciences in cold and arid regions, 474-478 (2014)

21. S.A. Kudryavtsev, T.U. Valtseva, R.G. Mikhailin, E.D. Goncharova, Using designs of variable rigidity on weak soils roads in the Russian Far East 6th International geotechnical symposium on Disasters Mitigation in Special Geoenvironmental Conditions (2015)

22. S.A. Kudryavtcev, V.M. Ulitskii, V.N. Paramonov, I.I. Sakharov, Soil mechanics and foundation engineering 52(5), 240-246 (2015) 